\title{
Avaliação da adesão a terapia antirretroviral com esquemas contendo dolutegravir em um município de Goiás
}

\author{
Assessment of adherence to antiretroviral therapy schemes containing dolutegravir in a \\ municipality of Goiás \\ Evaluación de la adhesión a la terapia antirretroviral con esquemas que contienen dolutegravir en \\ un municipio de Goiás
}

Recebido: 10/05/2021 | Revisado: 18/05/2021 | Aceito: 23/05/2021 | Publicado: 08/06/2021

Thalita Brunna Fernandes da Costa

ORCID: https://orcid.org/0000-0002-6138-9852 Centro Universitário de Anápolis - UniEVANGÉLICA, Brasil

E-mail: thalitabrunna@hotmail.com

Álice Cristina Borges Morais

ORCID: https://orcid.org/0000-0003-4371-054X Centro Universitário de Anápolis - UniEVANGÉLICA, Brasil E-mail: alicecristina49@gmail.com

Karolyne Gomes Miranda

ORCID: https://orcid.org/0000-0002-0003-8133 Centro Universitário de Anápolis - UniEVANGÉLICA, Brasil E-mail: karolyne_.gm@hotmail.com

Luane da Silva Oliveira Siqueira ORCID: https://orcid.org/0000-0003-0998-5304 Universidade Federal de Goiás, Brasil E-mail: luanebiel@hotmail.com

Gabriel Dutra de Jesus Siqueira ORCID: https://orcid.org/0000-0003-3007-2120 Universidade Federal de Goiás, Brasil E-mail: siqueiragdj@gmail.com

José Luís Rodrigues Martins

ORCID: https://orcid.org/0000-0003-3516-5350 Centro Universitário de Anápolis- UniEVANGÉLICA, Brasil E-mail: jlfarmacia@hotmail.com

Marcelo Cecílio Daher

ORCID: https://orcid.org/0000-0002-9975-558X Centro Universitário de Anápolis - UniEVANGÉLICA, Brasil E-mail: marceloceciliodaher@gmail.com

Aline de Araújo Freitas

ORCID: https://orcid.org/0000-0002-4480-4882 Centro Universitário de Anápolis - UniEVANGÉLICA, Brasil E-mail: alinefreitas2@gmail.com

Emerith Mayra Hungria Pinto ORCID: https://orcid.org/0000-0002-3731-0817 Centro Universitário de Anápolis - UniEVANGÉLICA, Brasil E-mail: emerith.pinto@docente.unievangelica.edu.br

\begin{abstract}
Resumo
As pessoas infectadas pelo Vírus da Imunodeficiência Humana (HIV) têm acesso gratuito a Terapia Antirretroviral (TARV), no entanto para que funcione é preciso que o paciente conduza a manutenção do tratamento, pois a efetividade da TARV depende diretamente da adesão do paciente. O objetivo do presente estudo foi descrever a adesão à TARV de pacientes com HIV/AIDS atendidos pelo Sistema Único de Saúde no Estado de Goiás. Trata-se de um estudo descritivo transversal, desenvolvido na unidade de saúde Dr. Ilion Fleury Jr., referência em diagnóstico e tratamento de ISTs/AIDS na cidade de Anápolis/GO. O "Cuestionario para La evaluación de La adhesión al tratamiento antirretroviral - CEAT$V I H$ ” foi utilizado para avaliar a adesão a TARV. Os prontuários dos pacientes foram analisados para obtenção dos resultados laboratoriais. Entre os 88 pacientes incluídos no estudo 74\% (n=65) eram do sexo masculino, com média de idade de 37 anos e 49\% (n=43) se declararam heterossexuais. Ao analisar a adesão foi constatado que 81\% ( $\mathrm{n}=72$ ) presentaram adesão estrita, mais de $87 \%$ dos participantes possuíam carga viral não detectável, com uma contagem de linfócitos TCD4+ de \pm 555 células $/ \mathrm{mm}^{3}$. Os resultados desse estudo permitem sugerir uma boa adesão ao novo esquema de TARV com dolutegravir, além de melhor controle de carga viral.
\end{abstract}


Palavras-chave: Adesão à medicação; Saúde pública; Terapia antirretroviral de alta atividade.

\begin{abstract}
Individual infected with the Human Immunodeficiency Virus (HIV) have free access to Antiretroviral Therapy (ART), however for it to work it is necessary that the patient conducts the maintenance of the treatment, as the effectiveness of ART depends directly on the patient's compliance. The aim of the present study was to describe the adherence to ART of patients with HIV / AIDS treated by the Unified Health System in the State of Goiás. This is a cross-sectional descriptive study, developed at the health unit Dr. Ilion Fleury Jr., reference in diagnosis and treatment of STIs / AIDS in the city of Anápolis / GO. The "Survey for the assessment of adhesion to antiretroviral treatment - CEAT-HIV" was used to assess adherence to ART. The patients' medical records were analyzed to obtain laboratory results. Among the 88 patients included in the study, $74 \%(n=65)$ were male, with a mean age of 37 years and $49 \%(n=43)$ declared themselves to be heterosexual. When analyzing adherence, it was found that $81 \%(\mathrm{n}=72)$ had strict adherence, more than $87 \%$ of the participants had an undetectable viral load, with a TCD4 + lymphocyte count of \pm 555 cells $/ \mathrm{mm}^{3}$. The results of this study allow us to suggest a good adherence to the new ART scheme with dolutegravir, in addition to better viral load control.
\end{abstract}

Keywords: Medication adherence; Highly active; Public health; Antiretroviral therapy.

\title{
Resumen
}

Las personas infectadas con el Virus de la Inmunodeficiencia Humana (VIH) tienen libre acceso a la Terapia Antirretroviral (TAR), sin embargo para que funcione es necesario que el paciente realice el mantenimiento del tratamiento, ya que la efectividad de la TAR depende directamente del cumplimiento del paciente. El objetivo del presente estudio fue describir la adherencia al TARV en pacientes con VIH / SIDA atendidos por el Sistema Único de Salud del Estado de Goiás, estudio descriptivo transversal, desarrollado en la unidad de salud Dr. Ilion Fleury Jr ., referente en diagnóstico y tratamiento de ITS / SIDA en la ciudad de Anápolis / GO. Se utilizó la "Encuesta para la evaluación de la adherencia al tratamiento antirretroviral - CEAT-VIH" para evaluar la adherencia al TAR. Se analizaron las historias clínicas de los pacientes para obtener resultados de laboratorio. De los 88 pacientes incluidos en el estudio, el 74\% ( $n=65)$ eran varones, con una edad media de 37 años y el 49\% $(n=43)$ se declaraba heterosexual. $\mathrm{Al}$ analizar la adherencia se encontró que el $81 \%(\mathrm{n}=72)$ tenía adherencia estricta, más del $87 \%$ de los participantes tenían una carga viral indetectable, con un recuento de linfocitos TCD4 + de \pm 555 células / $\mathrm{mm}^{3}$. Los resultados de este estudio nos permiten sugerir una buena adherencia al nuevo régimen ARV con dolutegravir, además de un mejor control de la carga viral.

Palabras clave: Adherencia a la medicación; Salud pública; Terapia antirretroviral de gran actividad.

\section{Introdução}

A Síndrome de Imunodeficiência Adquirida (AIDS) surgiu como nova entidade nosológica no início da década de 1980. Constitui-se como uma manifestação clínica avançada da infecção pelo Vírus de Imunodeficiência Humana (HIV), que gera imunodeficiência grave e pode acarretar o surgimento de infecções e neoplasias associadas, podendo levar à morte (Nunn et al., 2007).

A AIDS, por seu caráter pandêmico e gravidade, representa um problema mundial de saúde pública. Durante as últimas décadas a disponibilidade dos medicamentos antirretrovirais levou à diminuição relevante da morbimortalidade relacionada ao HIV/AIDS e ao aumento da qualidade de vida de pessoas vivendo com HIV/AIDS (PVHA). A introdução da terapia antirretroviral (TARV) desenvolveu o potencial de transformar a AIDS em uma doença crônica, com possibilidade de controle. Contudo, o HIV/AIDS ainda não tem cura e a eficácia do tratamento depende necessariamente da adesão à TARV por toda a vida (Polejack \& Seidl, 2010).

A adesão a um fármaco envolve sua tomada na dose e frequência prescritas, mas não há consenso para definições da boa e má adesão (Rocha et al., 2011). Os primeiros estudos sobre adesão descreveram que pelo menos 95\% de adesão à TARV seria necessária para manter a carga viral (CV) do HIV indetectável e consequentemente haveria uma diminuição da morbimortalidade (Ehlers \& Tshisuyi, 2015).

A Organização Mundial da Saúde (OMS) define a adesão como o grau de comportamento da pessoa em consonância com as recomendações dos profissionais da saúde. Esse comportamento se remete a tomar o medicamento, seguir uma dieta e executar mudanças em sua vida. Além disso, a OMS também esclarece que a adesão envolve cinco dimensões: fatores 
socioeconômicos, fatores relacionados ao paciente, fatores relacionados à doença, fatores relacionados ao tratamento, e o sistema e equipe de saúde (WHO, 2003). Entre os principais fatores que afetam a adesão no início do uso da TARV estão às reações adversas aos medicamentos, número de comprimidos administrados, nível de escolaridade e presença de sintomas preditores da AIDS (Cardoso et al., 2019). Além destes iniciais, existem outros fatores que são altamente significativos e que também interferem na adesão, como o abuso de substâncias lícitas e ilícitas, depressão, estigma, restrições financeiras, status de emprego, idade e saúde mental (Paramesha \& Chacko, 2019).

A adesão é uma das principais variáveis nas quais os serviços de saúde podem intervir para aumentar a eficácia do tratamento do HIV/AIDS, a identificação de fatores preditivos para a não adesão permite que o sistema de saúde adote medidas para otimizar a adesão e para o estabelecimento de informações destinadas ao sistema de vigilância (Cardoso et al., 2019).

Atualmente, a TARV pode ser composta pela combinação de fármacos das seguintes classes: inibidores da transcriptase reversa análogos de nucleosídeos (NRTIs), inibidores da transcriptase reversa análogos não nucleosídeos (NNRTI), inibidores da protease viral (PI), inibidores da integrase (INSTI), inibidores de entrada (IE) e de fusão (IF) (BRASIL, 2018).

No Brasil até janeiro de 2017, o regime de tratamento preferencial de TARV era composto por tenofovir (TDF), lamivudina (3TC) e efavirenz (EFV). Em fevereiro de 2017, houve atualização do esquema e o fármaco dolutegravir (DTG) passou a substituir o EFV no regime de primeira linha para indivíduos que iniciaram a TARV. (BRASIL, 2018) O DTG é um INSTI de nova geração que apresenta algumas vantagens em relação a outros fármacos, como a alta barreira genética, maior probabilidade de alcançar supressão viral, menor interação medicamentosa, menor probabilidade de reações adversas e por isso menor índice de descontinuação (Cruciani \& Parisi, 2019).

A adesão do paciente à TARV precisa ser monitorada clinicamente e cientificamente. É importante que se conheça o perfil de adesão dos pacientes com HIV/AIDS a todos os esquemas disponíveis TARV, considerando sua importância, entendese que a sistematização dos fatores associados à adesão já identificados é útil para pensar estratégias de saúde pública. Desse modo, o objetivo do presente estudo foi descrever a adesão a TARV em pacientes com HIV/AIDS atendidos pelo Sistema Único de Saúde no estado de Goiás.

\section{Metodologia}

Estudo qualitativo, descritivo, de caráter transversal desenvolvido no ambulatório Dr. Ilion Fleury Jr., unidade de referência no manejo de Infecções Sexualmente Transmissíveis (ISTs), em Anápolis/Goiás, munícipio com aproximadamente 386.923 habitantes, o terceiro maior município em população do estado de Goiás segundo o último senso do IBGE (2019). A população incluída no estudo foi composta por PVHA, maiores de 18 anos e que estavam em acompanhamento na Unidade Dr. Ilion Fleury Júnior a mais de seis meses. A coleta de dados ocorreu durante o período de abril a novembro de 2019.

Foram incluídos nesse estudo 88 pessoas com HIV/AIDS em uso do novo esquema preferencial de tratamento (3TC + TDF + DTG), pacientes que estavam em tratamento com o antigo regime (3TC + TDF + EFV) e fizeram switch para o novo esquema contendo DTG e pacientes que tiveram o DTG incluído em seu regime de tratamento, em acompanhamento no serviço a mais de 6 meses, de ambos os sexos que aceitaram participar do estudo, mediante leitura e assinatura do Termo de Consentimento Livre e Esclarecido (TCLE). Não foram incluídos no estudo, pessoas em uso de terapia ARV sob acompanhamento em serviço privado, as quais utilizaram o serviço público apenas para o recebimento dos medicamentos que compõe a terapia ARV, pois tais pacientes não recebiam atendimento sistemático ou não tinham registros nos prontuários do serviço, gestantes e menores de 18 anos.

Os pacientes que participaram voluntariamente da pesquisa foram expostos a riscos relacionados ao constrangimento perante as perguntas do questionário. Para minimizar esse risco a entrevista foi realizada em sala reservada para esse fim e a aplicação do questionário foi realizada por acadêmica devidamente treinada. Entre os benefícios da pesquisa estão a possibilidade 
da Unidade de Saúde traçar estratégias específicas para melhorar a adesão nos grupos identificados na categoria de baixa adesão, visto que a não adesão, além de reduzir os benefícios individuais esperados com o tratamento, aumenta significativamente o risco de transmissão coletiva de vírus resistentes aos ARVs.

Os dados sócio-demográficos foram coletados por meio de um questionário padronizado e estruturado contendo informações sobre sexo, idade, raça, escolaridade, município de residência, rendimento mensal e estado civil. O questionário também possuía questões relativas ao tempo de diagnóstico de HIV/AIDS, forma de contaminação e uso de fármacos antirretrovirais.

Para avaliar a frequência de não adesão aos antirretrovirais, foi utilizado o instrumento Cuestionario para La Evaluación de La Adhesión al Tratamiento Antirretroviral (CEAT-VIH), validado no Brasil por Remor, Milner-Moskovics e Preussler (2007). Trata-se de um instrumento auto informe com 20 questões que avaliam o grau de adesão a TARV. A pontuação total é obtida pela soma dos 20 itens (valor mínimo possível 17, valor máximo possível 89). Se o valor bruto for entre 80 a 89 pontos, o paciente é considerado como estritamente aderente, entre 75 a 79 é considerada uma boa aderência ao tratamento e menor que 74 é classificado com pouco aderente ao tratamento. Esse questionário aborda questões que mostram alguns motivos que poderiam auxiliar ou prejudicar a adesão ao tratamento, tais como: deixou de tomar o medicamento por se sentir melhor, pior, triste ou deprimido? Que relação mantém com o prescritor? Utiliza alguma estratégia para lembrar e/ou facilitar a administração do medicamento? Tem alguma dificuldade em tomar os medicamentos? A ocorrência de reações adversas influencia na não adesão ao tratamento? Dentre outras.

A revisão de prontuários clínicos de todos os participantes foi realizada para obtenção de informações sobre a provável categoria de exposição, data do diagnóstico do HIV e antecedentes de infecções oportunistas nos últimos 12 meses e os resultados laboratoriais referentes à contagem de células T CD4+e valores da quantificação da CV do HIV. Para os pacientes com mais de um resultado de contagem de células $\mathrm{T}$ CD4+ e carga viral foram considerados os valores obtidos na data mais próxima à data da realização da entrevista. Os dados referentes aos efeitos adversos aos fármacos da TARV foram obtidos por meio da revisão de prontuários clínicos e dos exames laboratoriais provenientes do seguimento ambulatorial dos pacientes. Foram coletadas informações relacionadas ao início da TARV, mudanças de medicamentos e esquemas terapêuticos.

Esta pesquisa foi aprovada pelo comitê de ética do Centro Universitário de Anápolis - UniEVANGÉLICA com no CAAE 56845316.0.0000.5076 na Plataforma Brasil.

\section{Resultados}

\section{Características da população}

Entre 88 pacientes com HIV/AIDS incluídos no estudo, 74\% ( $\mathrm{n}=65)$ eram homens e a idade média foi de 37,47 anos $(18-67$ anos). Em termos de escolaridade, apenas $23 \%(n=20)$ dos participantes possuíam ensino superior completo e $43 \%$ $(\mathrm{n}=38)$ possuíam ensino médio completo. Dos 88 participantes, 52\% $(\mathrm{n}=46)$ possuíam renda de um salário mínimo, 49\% ( $\mathrm{n}=$ 43) se declararam como heterossexuais. Para $97 \%(n=86)$ a provável forma transmissão foi pela via sexual. A Tabela 1 descreve os dados sociodemográficos do grupo de estudo.

Dentre os pacientes avaliados, o tempo de diagnóstico da infecção pelo HIV foi de 3,6 anos (variando de 6 meses - 22 anos), com 83\% ( $\mathrm{n}=73$ ) dos pacientes com tempo de diagnóstico da infecção pelo HIV menor que cinco anos. 
Tabela 1 - Características sociodemográficas de pessoas vivendo com HIV/AIDS atendidas em um centro de referência em Anápolis, Goiás, Brasil, de abril a novembro de 2019 ( $\mathrm{n}=88)$.

\begin{tabular}{|c|c|c|}
\hline Variáveis & $\mathbf{N}$ & $\%$ \\
\hline \multicolumn{3}{|l|}{ Sexo } \\
\hline Masculino & 65 & 73,8 \\
\hline Feminino & 23 & 26,1 \\
\hline \multicolumn{3}{|l|}{ Orientação sexual } \\
\hline Homossexual & 36 & 40,9 \\
\hline Heterossexual & 43 & 48,8 \\
\hline Bissexual & 9 & 10,2 \\
\hline \multicolumn{3}{|l|}{ Idade (anos) } \\
\hline $18-39$ & 47 & 53,4 \\
\hline $40-59$ & 38 & 43,1 \\
\hline$>60$ & 3 & 3,4 \\
\hline \multicolumn{3}{|l|}{ Situação conjugal } \\
\hline Solteiro & 59 & 67,0 \\
\hline Casado & 19 & 21,6 \\
\hline Divorciado & 6 & 6,8 \\
\hline Outros & 4 & 4,5 \\
\hline \multicolumn{3}{|l|}{ Categoria de Exposição } \\
\hline Sexual & 86 & 97,7 \\
\hline Sanguínea & 1 & 1,1 \\
\hline Acidente com perfuro-cortante & 1 & 1,1 \\
\hline \multicolumn{3}{|l|}{ Nível Escolar } \\
\hline Analfabeto & 7 & 7,9 \\
\hline Ensino Fundamental & 19 & 21,5 \\
\hline Ensino Médio & 38 & 43,1 \\
\hline Ensino Superior & 20 & 22,7 \\
\hline Pós-graduação, Mestrado e Doutorado. & 4 & 4,5 \\
\hline \multicolumn{3}{|l|}{ Renda Familiar } \\
\hline Até um salário mínimo & 46 & 52,2 \\
\hline Dois salários mínimos & 24 & 27,2 \\
\hline Mais de dois salários mínimos & 18 & 20,4 \\
\hline
\end{tabular}

Fonte: dos Autores.

\section{Avaliação da adesão a TARV}

Os resultados da avaliação da adesão à TARV utilizando CEAT-VIH indicaram que $81 \%(\mathrm{n}=72)$ dos pacientes apresentaram adesão estrita, 17\% $(n=14)$ apresentaram adesão classificada como boa e apenas 3\% (n= 2) apresentaram baixa adesão. Quando realizada a correção de Bonferroni para realizar comparações múltiplas, foi observado que o grupo com adesão estrita apresentou maior idade que o grupo de boa adesão $(\mathrm{p}<0,024)$.

Dentre os 88 pacientes incluídos no estudo existem dois grandes grupos, (1) pacientes que faziam uso do esquema preferencial de tratamento TARV (3TC + TDF + DTG), sendo esse grupo composto por 72 pacientes; e (2) pacientes que possuem em seu esquema de tratamento o DTG, com um total de 16 pacientes nesse grupo. 
Entre os 16 pacientes que possuem o DTG em seu esquema (grupo 2), 56,2\% (n=9) eram do sexo feminino com idades entre 17 e 50 anos, todos apresentaram estrita adesão a TARV e carga viral indetectável.

Na Tabela 2 demonstra-se os dados de ambos os grupos de pacientes, com associação entre variáveis demográficas, clínicas e laboratoriais segundo a adesão à TARV avaliada pelo CEAT-VIH.

Estudo anterior de Oliveira e colaboradores (2018) na cidade de Anápolis também avaliou o nível de adesão relacionado ao esquema anterior de TARV composto por Tenofovir, Lamivudina e Efavirenz, contou com 220 pacientes e em torno de $86 \%$ $(n=188)$ dos pacientes tiveram adesão boa ou estrita à terapia a TARV e 14\% $(n=32)$ apresentaram baixa adesão. O uso de drogas ilícitas foi associado à baixa adesão à terapia antirretroviral, não sendo observada associação significativa entre os níveis de adesão e outros dados sociodemográficos. Considerando a adesão verificada no presente estudo, o teste de qui-quadrado de aderência mostrou que os dados obtidos não são consistentes com a distribuição verificada por Oliveira et al. 2018.

Tabela 2 - Associação entre variáveis sociodemográficas, clínicas e laboratoriais e adesão à TARV dos 72 pacientes em uso esquema preferencial de tratamento, Anápolis, Goiás, Brasil, de abril a novembro de $2019(\mathrm{n}=72)$.

Classificação do nível de adesão a TARV

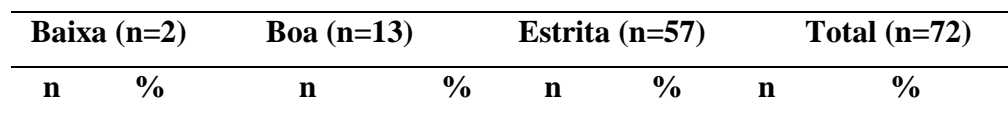

\begin{tabular}{|c|c|c|c|c|c|c|c|c|}
\hline \multicolumn{9}{|l|}{ Sexo } \\
\hline Feminino & 0 & 0 & 3 & 1 & 13 & 18 & 16 & 22,2 \\
\hline Masculino & 2 & 2,7 & 10 & 13,8 & 44 & 61,1 & 56 & 77,7 \\
\hline \multicolumn{9}{|l|}{ Idade } \\
\hline $18 \mid-40$ & 1 & 1,3 & 11 & 15,2 & 32 & 44,4 & 44 & 61,1 \\
\hline $41 \mid-50$ & 1 & 1,3 & 2 & 2,7 & 16 & 22,2 & 19 & 26,3 \\
\hline$>50$ & 0 & 0 & 0 & 0 & 9 & 12,5 & 9 & 12,5 \\
\hline \multicolumn{9}{|c|}{ Orientação Sexual } \\
\hline Heterossexual & 2 & 2,7 & 3 & 4,1 & 26 & 36,1 & 31 & 43,0 \\
\hline Homossexual & 0 & 0 & 10 & 13,9 & 25 & 34,7 & 35 & 48,6 \\
\hline Bissexual & 0 & 0 & 0 & 0 & 6 & 8,3 & 6 & 8,3 \\
\hline \multicolumn{9}{|c|}{ LTCD4 $^{+}\left(\right.$céls/mm $\left.{ }^{3}\right)$} \\
\hline$<500$ & 1 & 1,3 & 5 & 6,9 & 30 & 41,6 & 36 & 50 \\
\hline$>500$ & 1 & 1,3 & 8 & 11,1 & 27 & 37,5 & 36 & 50 \\
\hline \multicolumn{9}{|l|}{ Carga viral } \\
\hline Indetectável & 1 & 1,3 & 10 & 13,9 & 49 & 68,0 & 60 & 83,3 \\
\hline$<500$ & 0 & 0 & 3 & 4,1 & 8 & 11,1 & 11 & 15,2 \\
\hline$>500$ & 1 & 1,3 & 0 & 0 & 0 & 0 & 1 & 1,3 \\
\hline \multicolumn{9}{|c|}{ Tempo de diagnóstico } \\
\hline$<5$ & 2 & 2,7 & 12 & 16,6 & 50 & 69,4 & 64 & 88,8 \\
\hline $5 \mid-10$ & 0 & 0 & 0 & 0 & 4 & 5,5 & 4 & 5,5 \\
\hline$>10$ & 0 & 0 & 1 & 1,3 & 3 & 4,1 & 4 & 5,5 \\
\hline \multicolumn{9}{|c|}{ Consumo de álcool } \\
\hline Sim & 2 & 2,7 & 7 & 9,7 & 26 & 36,1 & 35 & 48,6 \\
\hline Não & 0 & 0 & 6 & 8,3 & 31 & 43 & 37 & 51,3 \\
\hline
\end{tabular}

Uso de drogas ilícitas

$\begin{array}{lllllllll}\text { Sim } & 1 & 1,3 & 5 & 6,9 & 8 & 11,1 & 14 & 19,4\end{array}$




\begin{tabular}{lcccccccc} 
Não & 1 & 1,3 & 8 & 11,1 & 49 & 68 & 58 & 80,5 \\
\hline Efeitos adversos a TARV & & & & & & & & \\
Muito intenso & 0 & 0 & 3 & 4,1 & 1 & 1,3 & 4 & 5,5 \\
Intermediário & 1 & 1,3 & 2 & 2,7 & 10 & 13,8 & 13 & 18,0 \\
Não intenso & 1 & 1,3 & 8 & 11,1 & 46 & 63,8 & 55 & 76,3 \\
\hline Coinfecções & 1 & 1,3 & 7 & 9,7 & 21 & 29,1 & 29 & 40,2 \\
Sim & 1 & 1,3 & 6 & 8,3 & 36 & 50 & 43 & 59,7 \\
Não & & & & & & & & \\
\hline
\end{tabular}

Fonte: dos Autores.

\section{Acompanhamento laboratorial: contagem de linfócitos TCD4+ e Carga viral (CV)}

Avaliando-se a CV percebe-se que dos 88 pacientes em estudo, 87,5\% (n= 77) possuíam CV indetectável e apenas 12,5\% ( $\mathrm{n}=11) \mathrm{CV}$ detectável. Entre os pacientes com CV detectável a média foi de $\pm 338,36$ cópias $/ \mathrm{mL}$ (56 cópias $/ \mathrm{mL}-1.911$ cópias $/ \mathrm{mL})$. Em relação ao grupo $1(\mathrm{n}=72)$ verificou-se que $83 \%(\mathrm{n}=60 / 72)$ dos pacientes que possuíam CV indetectável e foram classificados com adesão estrita a TARV mediante a avaliação pelo formulário CEAT-VIH. Entre os pacientes desse grupo com CV detectável (n=11), 81,81\% eram homens (9/11) e 90,91\% (10/11) tiveram adesão classificada com boa ou estrita.

Entre os 88 pacientes avaliados, a contagem de linfócitos T CD4+ variou de 34 até 1.596 células $/ \mathrm{mm}^{3}{ }^{+} \pm 555,64$ células $/ \mathrm{mm}^{3}$ ). Com relação ao grupo $1(\mathrm{n}=72)$, pacientes em uso do esquema preferencial de TARV, a média da contagem dos pacientes classificados com adesão estrita a média foi de $\pm 545,88$ células $/ \mathrm{mm}^{3}$ ( $75-1.596$ células $\left./ \mathrm{mm}^{3}\right)$, nos pacientes com boa adesão ( $\mathrm{n}=13$ ) obteve-se média de $\pm 640,23$ células $/ \mathrm{mm}^{3}\left(272\right.$ - 1119 células $\left./ \mathrm{mm}^{3}\right)$ nos pacientes com baixa adesão a TARV $(\mathrm{n}=2)$ teve-se a média de \pm 592 células $/ \mathrm{mm}^{3}\left(453-731\right.$ células $\left./ \mathrm{mm}^{3}\right)$.

\section{Efeitos adversos e coinfecções}

Em relação aos efeitos adversos 79\% (70/88) dos pacientes declararam que os efeitos adversos associados a TARV eram nada intensos sendo que os mais relatados foram depressão associada a medicação, cefaleia, insônia, êmese, náuseas, dor no estômago, tontura e diarreia. Dentre esses pacientes $(n=70)$ os pacientes com relato de efeitos adversos intensos ou muitos intensos, foram 5,71\% ( $n=4 / 70)$, os efeitos mais relatados foram depressão associada a medicação e náusea. Na avaliação dos prontuários clínicos as alterações laboratoriais mais frequentemente encontradas foram: plaquetopenia, hematúria, e proteinúria.

Com base nos dados do seguimento ambulatorial, 37\% (33/88) dos pacientes avaliados apresentaram coinfecções. A maioria dos pacientes com coinfecções (84\%, 28/33) eram homens. A coinfecção mais frequente foi sífilis (36\%, 12/33), seguida de hepatite B $(24 \%, 8 / 33)$ e herpes-zóster $(9 \%, 3 / 33)$. As outras coinfecções presentes foram: pneumonia $(6 \%, 2 / 33)$, colite por citomegalovírus $(3 \%, 1 / 33)$, hepatite C $(3 \%, 1 / 34)$, neurotoxoplasmose $(3 \%, 1 / 33)$, candidíase oral $(3 \%$, 1/33), candidíase esofágica $(3 \%, 1 / 33)$, infecção por Tinea cruris $(3 \%, 1 / 33)$, herpes-simples $(3 \%, 1 / 33)$ e tuberculose $(3 \%, 1 / 33)$.

\section{Discussão}

A adesão ao tratamento antirretroviral por pacientes portadores do HIV é de extrema importância por promover elevação da qualidade de vida, redução das morbidades e aumento da sobrevida (Silva et al., 2017). Entretanto, a adesão é um dos maiores desafios da equipe multidisciplinar, posto que é influenciada por fatores relacionados às alterações físicas, fisiológicas e psicológicas induzidas pela própria síndrome e pelo tratamento. Além disso, a adesão ao tratamento sofre influência da personalidade do paciente, do envolvimento e empatia com a equipe de saúde multiprofissional e das interações sociais (Schaurich, Coelho, \& Motta, 2006). 
No caso da avaliação da adesão à TARV existem poucos estudos no Brasil, e até o ano de 2017, nenhum havia sido feito no Centro-Oeste, sendo que havia uma alta taxa de não adesão a TARV na outras regiões do país, com os valores variando de $18 \%$ a $74,3 \%$ (Garbin, Gatto, \& Garbin, 2017). Nosso estudo foge dessa variação, apresentando $81 \%$ dos pacientes com adesão estrita à TARV, e segue o mesmo padrão do primeiro estudo feito em Anápolis, com 85\% dos pacientes apresentando boa ou estrita adesão à TARV até o ano de 2017. Vale ressaltar que a adesão pode variar dentro de um mesmo país ou de uma região para outra, evidenciando o aspecto heterogêneo da infecção pelo HIV/AIDS, da adesão à TARV e dos fatores associados à mesma (Carvalho, Barroso, Coelho \& Penaforte, 2019).

Um ponto que pode ter influenciado na diferença do nível de adesão entre os estudos de outras regiões do país é o esquema de tratamento analisado. Avaliamos esquemas que contém o DTG, que desde a sua aprovação em 2014, ganhou rapidamente um lugar de destaque na terapêutica antirretroviral (Moraes et al., 2019). Pesquisas que avaliam a adesão especificamente em regimes contendo DTG são escassos. Um estudo comparativo de esquema medicamentoso com DTG versus EFV, que era o medicamento utilizado no último esquema preferencial junto ao TDF + 3TC, evidencia que, em relação a prevalência geral de adesão, o grupo contendo DTG apresentou o maior percentual de pacientes aderentes do que o que contendo EFV. O perfil de eventos adversos também diferiu entre os grupos, sendo menor no grupo contendo DTG, e pode ter contribuído para aumentar a chance de melhor adesão à TARV (Cardoso et al., 2019). Esquemas contendo DTG também levam a um custo médio mensal menor do que esquemas comparados sem DTG, principalmente se for usado como primeira linha de tratamento. (Guillén et al., 2017).

Os efeitos adversos prevalentes associados ao DTG são efeitos neuropsiquiátricos (ENP), sendo insônia, nervosismo/ansiedade e humor depressivo os mais documentados, contudo esses efeitos não levam à descontinuação do DTG nos pacientes com HIV, o que pode ser explicado por serem autolimitados e sem impacto significativo nas atividades de vida diária (Moraes et al., 2019). Na nossa pesquisa 79\% os pacientes declararam que os efeitos adversos eram nada intensos, e dentre os mais relatados houve a presença de ENP. Isso evidencia que mesmo que não seja um fator de descontinuidade é importante detectar precocemente os ENP com o objetivo de tratá-los para que estes não influenciem negativamente a adesão ao tratamento e a qualidade de vida das PVHA (Santos, Silva, Santana, \& Teixeira, 2016).

Além de reações adversas, outros fatores que envolvem a baixa na adesão são déficit de suporte familiar e social e consumo de bebida alcoólica e substâncias psicoativas (Cabral et al., 2018). Por outro lado, o diagnóstico de AIDS melhora a adesão à terapia antirretroviral e a probabilidade de não adesão ao tratamento antirretroviral é reduzida entre os indivíduos que desenvolvem a doença. Isso aponta que os indivíduos sintomáticos aderem com mais frequência ao tratamento. Outras variáveis consideradas como potenciais fatores de risco para a não adesão, como escolaridade e estado civil, não apresentam associação significativa (Velame, Silva, Cerutti, \& Junior, 2020).

Considerando as variáveis laboratoriais, a contagem de LT CD4+ tem importância na avaliação inicial, enquanto a CV é considerada o padrão-ouro para monitorar a eficácia da TARV e detectar precocemente problemas de adesão em PVHA (BRASIL, 2018). Com relação à CV, nossos resultados apontam que 12,5\% pacientes tiveram CV detectável. Um estudo em Vitória - ES, mostrou que mesmo em pacientes considerados aderentes ao tratamento existe também presença de CV detectável (Velame et al., 2020). CV detectável em pacientes aderentes sugerem falha da adesão à TARV, e consequentemente falha virológica, que é definida como CV detectável após seis meses do início ou da modificação do tratamento, ou rebote da CV em indivíduos que haviam atingido supressão viral sob tratamento (BRASIL, 2018). Ou seja, existem mais pacientes que mantém a baixa adesão do que foi detectado por meio CEAT- VIH, pois a CV é um importante marcador da qualidade da adesão ao tratamento (Soares, Brito, Lima, \& Lapa, 2019).

Dados do seguimento ambulatorial evidenciaram que 37\% dos pacientes com HIV/AIDS apresentaram coinfecções, sendo que as mais frequentes foram sífilis (36\%), seguida de hepatite B (24\%) e herpes zóster (9\%). A sífilis também tinha a 
maior incidência (40\%) no ano de 2017, seguida pela tuberculose (15\%), contudo, contrapondo esse dado, nossa pesquisa evidenciou apenas um caso de coinfecção por tuberculose (Oliveira et al., 2018).

\section{Considerações Finais}

Em nosso estudo a maioria dos pacientes apresentaram adesão classificada como estrita ou boa (81\%), o que pôde ser confirmado pelos resultados laboratoriais, visto que 87,5\% dos pacientes apresentavam CV indetectável. Além disso, a alta taxa de adesão estava correlacionada aos baixos níveis de efeitos adversos relatados pelos pacientes. Apenas 3\% dos pacientes foram classificados com baixa adesão pelo CEAT-VIH, embora 12,5\% tivessem CV detectável, caracterizando laboratorialmente a falta de adesão a TARV, esses pacientes eram na sua maioria do sexo masculino. É imprescindível dar seguimento à monitorização das taxas de não adesão, bem como avaliar as dificuldades que levam os pacientes a desistência do tratamento, e dessa forma subsidiar ações específicas voltadas para o enfrentamento desse problema nos grupos mais vulneráveis. A avaliação de um maior número de pacientes em múltiplas unidades de referência para tratamento da infecção por HIV/AIDS no Brasil e aplicação de métodos diretos e indiretos de avaliação da adesão a TARV é crucial para se encontrar as variáveis mais associadas a baixa adesão.

\section{Referências}

BRASIL MDS. (2018). Protocolo clínico e diretrizes terapêuticas para Profilaxia Pré-Exposição (PrEP) de risco à infecção pelo HIV. Ministério da Saúde Brasil.

Cabral, R. J., Moraes, D. C. A., Cabral, L. R., Corrêa, C.A., Oliveira E. C. S., \& Oliveira, R. C. (2018) Adesão à terapia antirretroviral e a associação no uso de álcool e substâncias psicoativas. Enfermería global, 17(4), 1-35.

Cardoso, T. S., Costa, J. O., Reis, E. A., Silveira, M. R., Bonolo, P. F., Santos, S. F., \& Ceccato, M. G. B.(2019). Which antiretroviral regimen is associated with higher adherence in Brazil? A comparison of single, multi, and dolutegravir-based regimens. Cad Saude Publica, $35: e 00115518$.

Carvalho, P. P., Barroso, S. M., Coelho, H. C., \& Penaforte, F. R. O. (2019) Factors associated with antiretroviral therapy adherence in adults: an integrative review of literature. Cien Saude Colet, 24, 2543-55.

Cruciani, M., \& Parisi, S. G. (2019) Dolutegravir based antiretroviral therapy compared to other combined antiretroviral regimens for the treatment of HIVinfected naive patients: A systematic review and meta-analysis. PLoS One, 14(9), e0222229.

Ehlers, V. J., \& Tshisuyi, E. T. (2015) Adherence to antiretroviral treatment by adults in a rural area of Botswana. Curationis, 38(1), 1-8.

Estrela, C. (2018). Metodologia Científica: Ciência, Ensino, Pesquisa. Editora Artes Médicas.

Garbin, C. A. S., Gatto, R. C. J., \& Garbin, A. J. I. (2017) Adesão à terapia antirretroviral em pacientes HIV soropositivos no Brasil: uma revisão da literatura. Archives of Health Investigation, 6(2), 65-70.

Guillén, S. M., García, J. E. L., Berenguer, J. B., Sesmero, J. M. M., Gomis, S. C., Graefehain, R., Sánchez-Cambronero D. L. \& García, F. J. P. (2017) Costutility analysis of the fixed-dose combination of dolutegravir/abacavir/lamivudine as initial treatment of HIV+ patients in Spain. Farm Hosp, 41(5), 601-610.

Moraes, R., Ferreira, M., Vaz, R., Coelho, I., Pinheiro, G., Gonçalves, J., França, M., \& Almeida, I. (2019) Prevalência de Efeitos Neuropsiquiátricos em Doentes com Infecção VIH sob Dolutegravir. Med Interna (Bucur), 26(1),14-20.

Nunn, A. S., Fonseca, E. M., Bastos, F. I., Gruskin, S., \& Salomon, J. A. (2007) Evolution of antiretroviral drug costs in Brazil in the context of free and universal access to AIDS treatment. PLoS Med. 2007;4(11):e305

Oliveira, L. S., Caixeta, L. M., Martins, J. L. R., Segati, K. D., Moura, R. S., Daher, M. C., \& Pinto, E. M. H. (2018) Adherence to antiretroviral therapy and correlation with adverse effects and coinfections in people living with HIV/AIDS in the municipality of Goiás State. Rev Soc Bras Med Trop, 51(4), 436-44.

Organization WH. (2003). Adherence to long-term therapies: evidence for action. World Health Organization.

Paramesha, A. E., \& Chacko, L. K. (2019) Predictors of adherence to antiretroviral therapy among PLHIV. Indian J Public Health, $63(4)$, 367.

Polejack, L., \& Seidl, E. M. F. (2010) Monitoramento e avaliação da adesão ao tratamento antirretroviral para HIV/aids: desafios e possibilidades. Psicologia, 70910,900 .

Remor, E., Milner-Moskovics, J., \& Preussler, G. (2007). Brazilian adaptation of the assessment of adherence to antiretroviral therapy questionnaire. Revista de saude publica, 41(5), 685-694.

Rocha, G. M., Machado, C. J., Acurcio, F. A., \& Guimarães, M. D. C. (2011) Monitoring adherence to antiretroviral treatment in Brazil: an urgent challenge. Cad Saude Publica, 27, s67-78. 
Research, Society and Development, v. 10, n. 6, e50910615963, 2021

(CC BY 4.0) | ISSN 2525-3409 | DOI: http://dx.doi.org/10.33448/rsd-v10i6.15963

Santos, É. I., Silva, A. L., Santana, P. P. C., \& Teixeira P. A. (2016) Evidências científicas brasileiras sobre adesão à terapia antirretroviral por pessoas que vivem com HIV/AIDS. Revista Eletrônica Gestão \& Saúde, (1), 454-70.

Schaurich, D., Coelho, D. F., \& Motta, M. G. C. (2006) A cronicidade no processo saúde-doença: repensando a epidemia da AIDS após os anti-retrovirais Revista Enfermagem UERJ, 14(3), 455-462.

Silva, R. A. R., Nelson, A. R. C., Duarte, F. H. S., Prado N. C. C., Holanda, J. R. R., \& Costa, D. A.R. S. (2017) Avaliação da adesão à terapia antirretroviral em pacientes com AIDS Evaluation of adherence to antiretroviral therapy for AIDS patients. Revista de Pesquisa Cuidado é Fundamental Online, 9(1), 15-20.

Soares, R. C. A., Brito, A. M., Lima, K., \& Lapa, T. M. (2019) Adherence to antiretroviral therapy among people living with HIV/AIDS in northeastern Brazil: a cross-sectional study. Sao Paulo Med J, 137(6), 479-85.

Velame, K. T., Silva, R. S., Cerutti, \& Junior, C. (2020) Factors related to adherence to antiretroviral treatment in a specialized care facility. Rev Assoc Med Bras, 66(3), 290-5. 